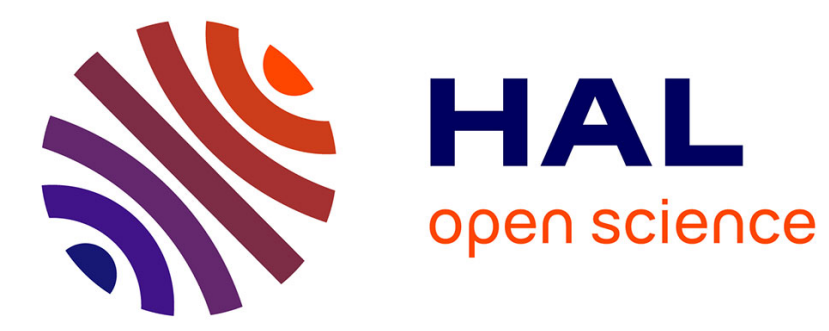

\title{
Estrogen receptor gene variants are associated with anxiety disorders in older women.
}

Joanne Ryan, Jacqueline Scali, Isabelle Carrière, Pierre-Yves Scarabin, Karen

A. Ritchie, Marie-Laure Ancelin

\section{- To cite this version:}

Joanne Ryan, Jacqueline Scali, Isabelle Carrière, Pierre-Yves Scarabin, Karen A. Ritchie, et al.. Estrogen receptor gene variants are associated with anxiety disorders in older women.. Psychoneuroendocrinology, 2011, epub ahead of print. 10.1016/j.psyneuen.2011.04.011 . inserm-00619147

\section{HAL Id: inserm-00619147 https://www.hal.inserm.fr/inserm-00619147}

Submitted on 5 Sep 2011

HAL is a multi-disciplinary open access archive for the deposit and dissemination of scientific research documents, whether they are published or not. The documents may come from teaching and research institutions in France or abroad, or from public or private research centers.
L'archive ouverte pluridisciplinaire HAL, est destinée au dépôt et à la diffusion de documents scientifiques de niveau recherche, publiés ou non, émanant des établissements d'enseignement et de recherche français ou étrangers, des laboratoires publics ou privés. 


\section{Estrogen receptor gene variants are associated with anxiety disorders in older women}

Joanne Ryan, $\mathrm{PhD}^{1,2,3, *}$, Jacqueline Scali ${ }^{1,2}$, MSc., Isabelle Carrière, PhD. ${ }^{1,2}$, Pierre-Yves Scarabin, MD., PhD. ${ }^{4}$, Karen Ritchie, PhD. ${ }^{1,2,5}$, Marie-Laure Ancelin, PhD. ${ }^{1,2}$

${ }^{1}$ Inserm, U1061, Montpellier, F-34093 France;

${ }^{2}$ Université Montpellier1, Montpellier, F-34000 France;

${ }^{3}$ Fondation FondaMental, Hopital Albert Chenevier, Creteil, France;

${ }^{4}$ Inserm, U1018, Université Paris Sud 11, F-94807 Villejuif, France;

${ }^{5}$ Faculty of Medicine, Imperial College, London, UK.

*Corresponding author at: Inserm U1061, Nervous System Pathologies: Epidemiological and Clinical Research. Hôpital La Colombière, 39 avenue Charles Flahault, BP 34493, 34093 Montpellier Cedex 5, France. Tel.: +33 499614565 ; Fax : +33 499614 579. E-mail address: joanne.ryan@inserm.fr (J.Ryan). 


\section{Summary}

Background: Estrogen is thought to play a key role in anxiety, but it remains unknown whether genetic variants in the estrogen receptors (ERs) can influence the risk of anxiety. This study investigated whether ESR1 and ESR2 gene variants were associated with specific anxiety disorders in postmenopausal women and evaluated the potential modifying effect of hormone treatment $(\mathrm{HT})$ on these associations.

Methods: One thousand and ninety-two community-dwelling women aged 65 years and older were recruited as part of the ESPRIT Study in Montpellier, France. Anxiety was assessed using the Mini-International Neuropsychiatry Interview (MINI), according to DSM-IV criteria. Two ESR1 and three ESR2 polymorphisms were genotyped.

Results: The most common anxiety disorders were phobia (14.2\%) and generalised anxiety disorder (GAD, 8\%). The A allele of ESR2 rs1256049 was associated with an increased risk of GAD [OR: 2.06, 95\% CI: 1.09-3.87], while both ESR1 polymorphisms were specifically associated with phobia. The C allele of ESR1 rs2234693 decreased the risk of phobia by $42 \%$ [95\% CI: 0.41-0.83], and this remained significant even after Bonferroni correction. The $\mathrm{G}$ allele of ESR1 rs9340799 was associated with a 31\% decreased phobia risk [95\% CI: 0.49-0.96]. There was also evidence of a significant gene-environment interaction, where only women who were currently using HT had a reduced risk of phobia with these ESR1 gene variants.

Conclusions: This study confirms earlier findings of an association between ESR1 and global anxiety in older women, however these associations varied depending on the anxiety syndrome and the use of HT. The results also suggest that the ESR2 may contribute to the genetic vulnerability to GAD, but these findings require further confirmation. 
Keywords: estrogen receptor ESR1 and ESR2; single nucleotide polymorphisms; anxiety; generalised anxiety disorder; phobia; elderly women; hormone treatment; association 


\section{Introduction}

Anxiety is the most prevalent psychiatric disorder affecting one in four adults across their lifetime (Kessler et al., 2005) and over 10\% of individuals in later-life (Ritchie et al., 2004). Female gender is a risk factor for later-life anxiety (Kessler et al., 2005), and evidence suggests the involvement of estrogen. Estrogen can influence the levels of neurotransmitters which have been directly implicated in anxiety, such as $\gamma$-aminobutyric acid (GABA), the major inhibitory neurotransmitter in the brain, and serotonin (5-HT) (Zinder and Dar, 1999). Estrogen upregulates GABA receptor expression and ligand binding and regulates 5-HT1A receptor number and function, thus controlling the activity of serotonergic neurons. In vitro and in vivo experiments have shown that estrogen treatment increases basal and stimulated extracellular GABA concentrations and stimulates serotonergic activity (see for review (Birzniece et al., 2006)). Studies using murine models have also demonstrated estrogen's anxiolytic effects (Walf and Frye, 2006).

Given the potential aetiological role of estrogen in anxiety, genes for the estrogen receptors (ERs) are obvious candidates implicated in this disorder. Indeed, studies in knock-out mice deficient in ESR1 or ESR2 genes support the involvement of these receptors in social recognition and anxiety (Walf and Frye, 2006). Only a very small number of studies in humans however, have examined the possibility that genetic variations in the ERs may influence the risk of anxiety. A study of children and adolescents reported an association between ESR1 gene variants and anxiety-related traits (Prichard et al., 2002), and ESR1 variants were recently associated with contamination obsessions and cleaning compulsions in young adult patients with obsessive-compulsive disorder (Alonso et al., 2011). In terms of late-life anxiety, the Rotterdam study reported that ESR1 haplotypes consisting of the T and A alleles of rs2234693 and 
rs9340799 respectively were associated with an increased risk of global anxiety level in 1335 older women (Tiemeier et al., 2005), however, to our knowledge, no subsequent study has sought to replicate these findings. Furthermore, prior studies have not examined ESR2, although evidence in mice suggests that ESR2 may be particularly important in modulating anxiety-like behavior (Walf and Frye, 2006).

Our study aimed to replicate and further the Rotterdam study's findings, by investigating the association between the same ESR1 gene variants and the most common anxiety disorders in this elderly female population (generalized anxiety-disorder [GAD] and phobia). Three ESR2 polymorphisms were also examined. Furthermore, as older postmenopausal women have low endogenous estrogen levels, we also investigated whether the use of estrogen-containing hormone treatment (HT) could modify the association between ER variants and anxiety.

\section{Method}

\subsection{Study Population}

Data were obtained from the ESPRIT study of psychiatric disorders in community-dwelling elderly (Ritchie et al., 2004). Eligible participants (aged at least 65 years and noninstitutionalised) were randomly selected from the electoral rolls in Montpellier, France. Of the people initially drawn at random, $27.3 \%$ did not participate. All procedures were carried out with the adequate understanding and written consent of the participants. The national ethics committee approved the study. Of the 1277 non-demented women recruited to the study, 185 were excluded from this analysis as they did not provide samples for genotyping analysis and/or were not assessed for anxiety disorders. Table 1 shows the participant's characteristics. 


\subsection{Anxiety disorders}

A standardized psychiatric examination validated in the general population, the MiniInternational Neuropsychiatry Interview (MINI) (Sheehan et al., 1998), was used for the diagnosis of current and past anxiety disorders (GAD, phobia, obsessive compulsive disorder, panic and post-traumatic stress disorder), according to DSM-IV criteria. Cases detected by the MINI were reviewed by a panel of psychiatrists to validate the initial diagnosis (Ritchie et al., 2004). Current use of anxiolytics, validated by presentation of the prescription or medication, was also recorded.

\subsection{Estrogen receptor polymorphisms}

DNA extracted from white blood cells (Puregene kit, Qiagen, France) was stored at $-80^{\circ} \mathrm{C}$. Genotyping was performed by Kbiosciences (Hoddesdon Herts, UK) using their competitive allele-specific PCR Single-Nucleotide Polymorphism (SNP) genotyping system (KASPar) which has an error rate of $<0.3 \%$. The ESR1 polymorphisms examined (rs2234693 and rs9340799), were the same as those analyzed previously in the Rotterdam study (Tiemeier et al., 2005). These SNPs are located at position 397 and 351 of intron 1 respectively, and they appear to be functionally significant (Maruyama et al., 2000; Alonso et al., 2011). Three ESR2 polymorphisms with unknown functional consequences but showing potential causal associations with other hormone-related health outcomes (Silvestri et al., 2006; Rexrode et al., 2007) were investigated: rs1256049 (position 1082 of exon 5), rs4986938 (position 1730 in the 3'-untranslated region of exon 8) and rs1271572 in the promoter region. Ninety-two percent of the population $(n=1004)$ had full genotyping data for all polymorphisms. 


\subsection{Hormone treatment}

Women stated whether they were current HT users, which was validated by presentation of the prescription or the medication itself. The majority of women (77.4\%) used transdermal estradiol (16.5\% unopposed, $22.6 \%$ combined with oral progesterone and 38.3\% synthetic progestin), and $15.8 \%$ used oral estradiol (14.2\% combined with synthetic progestin). Remaining women (6.8\%) used other forms of HT. No women used ethinylestradiol or conjugated equine estradiol.

\subsection{Statistical analysis}

Genotype deviation from the Hardy-Weinberg equilibrium was evaluated with a $\chi^{2}$ test, and pairwise linkage disequilibrium was estimated. Logistic regression models were used to estimate the association between the ER SNPs and anxiety disorders (GAD and phobia) assuming a dominant model (SAS v9.1, SAS Institute, Inc., NC). A first-order interaction between the SNPs and current HT use was also examined by including a product term in the models. When significant, subsequent analysis was stratified to determine independent group effects. Multivariate logistic models examined the potential confounding effect of age, education level, comorbidity, cognitive impairment or severe depression.

\section{Results}

Twenty-one percent of the population $(n=232)$ had a current anxiety disorder. GAD and phobia were the most prevalent, affecting $87(8 \%)$ and $155(14.2 \%)$ of the women respectively. Only 18 women were diagnosed with comorbid phobia and GAD. Other anxiety disorders (i.e. panic, 
obsessive-compulsive disorder and post-traumatic stress disorder) were rare among this elderly population $(\mathrm{n}=8)$. Compared to non-anxious women, those with anxiety differed on a number of socio-demographic health and lifestyle characteristics (Table 1).

All of the SNPs were in Hardy-Weinberg equilibrium. The ESR1 SNPs were in strong linkage disequilibrium $\left(\left|\mathrm{D}^{\prime}\right|=0.98\right)$, as were the three ESR2 SNPs $\left(\left|\mathrm{D}^{\prime}\right|>0.90\right.$ for all pairwise comparisons). Both ESR1 SNPs were significantly associated with the risk of phobia, with the variant alleles $\mathrm{C}$ and $\mathrm{G}$ of rs 2234693 and rs9340799 respectively, decreasing the risk by over $30 \%$ (Table 2 and supplementary Figure 1). None of the ESR2 polymorphisms were significantly associated with the risk of phobia, but the variant A allele of rs 1256049 was associated with a twofold increased risk of GAD. When an interaction term between these SNPs and HT was included in these models, there was evidence that current HT use could modify the association between ESR1 SNPs and phobia. For rs2234693 (interaction p=0.032) women who were using HT had a reduced risk of phobia with the C allele [170 women, OR: $0.28,95 \%$ CI: $0.12-0.64$, $\mathrm{p}=0.0025]$, while for women who had never used HT, this allele did not significantly modify the risk of phobia [699 women, OR: $0.79,95 \%$ CI: $0.49-1.28, \mathrm{p}=0.34]$. The findings were very similar for rs9340799 (interaction $\mathrm{p}=0.019$ ), where the A allele was associated with a decreased risk of phobia for HT users only [HT users, OR: 0.29, 95\% CI: 0.12-0.71, p=0.0064; never users, OR: $0.95,95 \%$ CI: $0.61-1.49, \mathrm{p}=0.83]$. These associations were not confounded by age, education level, comorbidity, cognitive impairment or severe depression. If a Bonferroni correction for multiple comparisons was applied, this would lower the significance threshold to 0.005 (five SNPs and two anxiety disorders), but the association between rs2234693 and the risk of phobia would still remain significant. Such a correction would, however, be overly 
conservative and increase the risk of a type 2 error, given that the tests were not independent (i.e. the SNPs are in strong linkage disequilibrium).

\section{Discussion}

Animal studies suggest that estrogen is anxiolytic and these effects can be mediated by the ERs (Walf and Frye, 2006). The estrogen-ER complex is capable of regulating the expression of hundreds of genes, including those involved in the synthesis and metabolism of various neurotransmitters in the brain. Genetic variation in the ER may therefore influence a person's risk of developing anxiety, but this has been insufficiently studied. The Rotterdam study of 1335 women aged over 55 years, found a significant association between ESR1 polymorphisms (rs2234693 and rs9340799) and global anxiety level (Tiemeier et al., 2005), but no subsequent study has attempted to replicate these findings or to examine whether this could vary across anxiety disorders. We report here that in older women these same ESR1 gene variants were specifically associated with the risk of phobia, but current HT use could modify this association. We also found that ESR2 rs1256049 was associated with the risk of GAD. Our study thus contributes important new findings to this field.

Although anxiety disorders often co-occur, there is a considerable degree of heterogeneity among the disorders and prior familial studies suggest a differential genetic component for GAD and phobia (Kendler et al., 1995). A large twin study also found that GAD, panic and agoraphobia shared common genetic risk factors that were distinct from those of other specific phobias. Social phobia shared some genetic components with both groups (Hettema et 
al., 2005). Our study adds to this research, reporting for the first time differential ER associations in elderly women across anxiety disorder.

The exact reason why these SNPs would be differential associated with phobia and GAD is unknown. The ESR1 rs2234693 and rs9340799 appear to be functionally significant, with the $\mathrm{C}$ and $\mathrm{G}$ alleles respectively being associated with higher gene expression (Maruyama et al., 2000; Alonso et al., 2011), and more favourable estrogen-dependent outcomes (i.e. bone mineral density (Ioannidis et al., 2002)). This could suggest that estrogen plays a important protective role against the risk of phobia in later life. The functional consequence of the ESR2 rs1256049 has not been established and it may be in linkage disequilibrium with other unidentified polymorphisms. Although ESR1 predominates in the amygdala and the hypothalamus (Walf and Frye, 2006), animal studies using ER subtype-specific compounds or animals deficient in one of the receptors suggest that ESR2 plays an important role in mediating estrogen's anxiolytic effects, and ESR1 may actually mediate estrogen's anxiogenic actions (Lund et al., 2005; Walf and Frye, 2006; Weiser et al., 2008). Our results contribute to a recent evidence indicating that ER polymorphisms can interact with HT to modify health outcomes, including bone mineral density (Silvestri et al., 2006), cholesterol levels (Herrington et al., 2002), and depression (Ryan et al., submitted manuscript). This is the first study to report that this gene-environment interaction may modify the risk of phobia. Despite reports that HT can improve psychological dysfunction, including anxiety symptoms in menopausal women, there is insufficient evidence to support a direct beneficial effect of HT in treating post-menopausal anxiety (Scali et al., 2009). These current results however, suggest that genetically, some women may respond more beneficially to HT in terms of psychiatric outcomes. 
This study is strengthened by its large population-based design and the use of a standardised psychiatric examination to assess specific anxiety disorders according to DSM-IV criteria, rather than just global anxiety like most previous studies. Our study is also one of the first to examine the association between ESR2 SNPs and anxiety. Study limitations include the possibility of population stratification which we could not control for because French law prohibits the collection of ethnic-related data. Genotype frequencies for both anxious and nonanxious participants were however, similar to those observed in Caucasian populations (Ioannidis et al., 2002; Rexrode et al., 2007). Duplicate genotyping was not performed, however the genotyping system used does have a very low error rate $(<0.3 \%)$. Replication of these results in other large population-based studies is needed.

Our findings provide further support for estrogen's anxiolytic effect, and indicate that certain women are genetically more susceptible to developing anxiety in later-life. This suggests the potential for developing specific ER-targeted hormone treatments for women most at risk of anxiety. 


\section{REFERENCES}

Alonso, P., Gratacos, M., Segalas, C., Escaramis, G., Real, E., Bayes, M., Labad, J., Pertusa, A., Vallejo, J., Estivill, X., Menchon, J.M., 2011. Variants in estrogen receptor alpha gene are associated with phenotypical expression of obsessive-compulsive disorder. Psychoneuroendocrinology. 36, 473-83.

Birzniece, V., Backstrom, T., Johansson, I.M., Lindblad, C., Lundgren, P., Lofgren, M., Olsson, T., Ragagnin, G., Taube, M., Turkmen, S., Wahlstrom, G., Wang, M.D., Wihlback, A.C., Zhu, D., 2006. Neuroactive steroid effects on cognitive functions with a focus on the serotonin and GABA systems. Brain Res Rev. 51, 212-39.

Herrington, D.M., Howard, T.D., Hawkins, G.A., Reboussin, D.M., Xu, J., Zheng, S.L., Brosnihan, K.B., Meyers, D.A., Bleecker, E.R., 2002. Estrogen-receptor polymorphisms and effects of estrogen replacement on high-density lipoprotein cholesterol in women with coronary disease. N Engl J Med. 346, 967-74.

Hettema, J.M., Prescott, C.A., Myers, J.M., Neale, M.C., Kendler, K.S., 2005. The structure of genetic and environmental risk factors for anxiety disorders in men and women. Arch Gen Psychiatry. 62, 182-9.

Ioannidis, J.P., Stavrou, I., Trikalinos, T.A., Zois, C., Brandi, M.L., Gennari, L., Albagha, O., Ralston, S.H., Tsatsoulis, A., 2002. Association of polymorphisms of the estrogen receptor alpha gene with bone mineral density and fracture risk in women: a metaanalysis. J Bone Miner Res. 17, 2048-60.

Kendler, K.S., Walters, E.E., Neale, M.C., Kessler, R.C., Heath, A.C., Eaves, L.J., 1995. The structure of the genetic and environmental risk factors for six major psychiatric disorders 
in women. Phobia, generalized anxiety disorder, panic disorder, bulimia, major depression, and alcoholism. Arch Gen Psychiatry. 52, 374-83.

Kessler, R.C., Berglund, P., Demler, O., Jin, R., Merikangas, K.R., Walters, E.E., 2005. Lifetime prevalence and age-of-onset distributions of DSM-IV disorders in the National Comorbidity Survey Replication. Arch Gen Psychiatry. 62, 593-602.

Lund, T.D., Rovis, T., Chung, W.C., Handa, R.J., 2005. Novel actions of estrogen receptor-beta on anxiety-related behaviors. Endocrinology. 146, 797-807.

Maruyama, H., Toji, H., Harrington, C.R., Sasaki, K., Izumi, Y., Ohnuma, T., Arai, H., Yasuda, M., Tanaka, C., Emson, P.C., Nakamura, S., Kawakami, H., 2000. Lack of an association of estrogen receptor alpha gene polymorphisms and transcriptional activity with Alzheimer disease. Arch Neurol. 57, 236-40.

Prichard, Z., Jorm, A.F., Prior, M., Sanson, A., Smart, D., Zhang, Y., Huttley, G., Easteal, S., 2002. Association of polymorphisms of the estrogen receptor gene with anxiety-related traits in children and adolescents: a longitudinal study. Am J Med Genet. 114, 169-76.

Rexrode, K.M., Ridker, P.M., Hegener, H.H., Buring, J.E., Manson, J.E., Zee, R.Y., 2007. Polymorphisms and haplotypes of the estrogen receptor-beta gene (ESR2) and cardiovascular disease in men and women. Clin Chem. 53, 1749-56.

Ritchie, K., Artero, S., Beluche, I., Ancelin, M.L., Mann, A., Dupuy, A.M., Malafosse, A., Boulenger, J.P., 2004. Prevalence of DSM-IV psychiatric disorder in the French elderly population. Br J Psychiatry. 184, 147-52.

Scali, J., Ryan, J., Carriere, I., Ritchie, K., Ancelin, M.L., 2009. A prospective study of hormonal treatment and anxiety disorders in community-dwelling elderly women (the Esprit Study). J Affect Disord. 115, 274-9. 
Sheehan, D.V., Lecrubier, Y., Sheehan, K.H., Amorim, P., Janavs, J., Weiller, E., Hergueta, T., Baker, R., Dunbar, G.C., 1998. The Mini-International Neuropsychiatric Interview (M.I.N.I.): the development and validation of a structured diagnostic psychiatric interview for DSM-IV and ICD-10. J Clin Psychiatry. 59, 22-33;quiz 34-57.

Silvestri, S., Thomsen, A.B., Gozzini, A., Bagger, Y., Christiansen, C., Brandi, M.L., 2006. Estrogen receptor alpha and beta polymorphisms: is there an association with bone mineral density, plasma lipids, and response to postmenopausal hormone therapy? Menopause. 13, 451-61.

Tiemeier, H., Schuit, S.C., den Heijer, T., van Meurs, J.B., van Tuijl, H.R., Hofman, A., Breteler, M.M., Pols, H.A., Uitterlinden, A.G., 2005. Estrogen receptor alpha gene polymorphisms and anxiety disorder in an elderly population. Mol Psychiatry. 10, 806-7.

Walf, A.A., Frye, C.A., 2006. A review and update of mechanisms of estrogen in the hippocampus and amygdala for anxiety and depression behavior. Neuropsychopharmacology. 31, 1097-111.

Weiser, M.J., Foradori, C.D., Handa, R.J., 2008. Estrogen receptor beta in the brain: from form to function. Brain Res Rev. 57, 309-20.

Zinder, O., Dar, D.E., 1999. Neuroactive steroids: their mechanism of action and their function in the stress response. Acta Physiol Scand. 167, 181-8. 
Table 1. Sociodemographic, lifestyle and health characteristics of the participants according to their anxiety status.

$\begin{array}{lcccc}\text { Characteristic } & \text { No anxiety } & \text { GAD } & \text { Phobia } & \text { Group difference } \\ (n=850) & (n=87) & (\mathbf{n}=155) & (\text { anxious vs. } \\ & & & \text { non-anxious })\end{array}$

\begin{tabular}{|c|c|c|c|c|c|}
\hline & & Mean (SD) & & $t$ test & $\mathbf{p}$ \\
\hline Age (years) & $73.2(5.7)$ & $71.9(5.4)$ & $72.0(4.9)$ & 1.87 & 0.06 \\
\hline \multirow[t]{2}{*}{$\operatorname{BMI}\left(\mathrm{kg} / \mathrm{m}^{2}\right)$} & $24.6(4.0)$ & $24.6(4.4)$ & $24.8(4.2)$ & -0.87 & 0.39 \\
\hline & & $\mathrm{N},(\%)$ & & $\chi^{2}(\mathbf{d f} \mathbf{1})$ & $\mathbf{p}$ \\
\hline$\geq 12$ yrs schooling & $272(28.0 \%)$ & $20(23.0 \%)$ & $25(16.1 \%)$ & 9.8 & 0.002 \\
\hline Married or living with others & $573(59.1 \%)$ & $49(56.3 \%)$ & $97(62.6 \%)$ & 0.09 & 0.77 \\
\hline Heavy drinker ( $\geq 24 \mathrm{~g}$ each day) & $51(5.4 \%)$ & $4(4.7 \%)$ & $8(5.3 \%)$ & 0.12 & 0.73 \\
\hline Heavy smoker (10 pack years) & $40(4.1 \%)$ & $5(5.8 \%)$ & $8(5.2 \%)$ & 0.32 & 0.57 \\
\hline Physical activity limitations ${ }^{\mathrm{a}}$ & $51(5.4 \%)$ & $3(3.6 \%)$ & $9(6.0 \%)$ & 0.39 & 0.53 \\
\hline Cognitive impairment $^{\mathrm{b}}$ & $296(30.6 \%)$ & $22(25.3 \%)$ & $59(38.3 \%)$ & 3.81 & 0.05 \\
\hline Comorbidity $^{\mathbf{c}}$ & $138(14.2 \%)$ & $18(20.7 \%)$ & $26(16.8 \%)$ & 3.65 & 0.06 \\
\hline Current use of hormone treatment & $132(13.9 \%)$ & $18(20.9 \%)$ & $28(18.5 \%)$ & 1.86 & 0.39 \\
\hline Severe current depression ${ }^{\mathrm{d}}$ & $156(16.2 \%)$ & $25(28.7 \%)$ & $47(30.5 \%)$ & 25.8 & $<0.001$ \\
\hline Current use of antidepressants & $72(7.4 \%)$ & $10(11.5 \%)$ & $13(8.4 \%)$ & 1.22 & 0.27 \\
\hline Current use of anxiolytics & $123(12.7 \%)$ & $12(13.8 \%)$ & $19(12.3 \%)$ & 1.09 & 0.30 \\
\hline
\end{tabular}

${ }^{\mathrm{a}}$ Unable to independently complete all tasks from the Instrumental Activities of Daily Living and the Activities of Daily Living scales.

${ }^{\mathbf{b}}$ Mini-Mental State Examination Score of less than 26. 
${ }^{\mathbf{c}} \mathrm{A}$ history of vascular disease [angina pectoris, myocardial infarction, stroke, cardiovascular surgery, bradycardia or palpitations], more than 1 chronic illnesses [asthma, diabetes (fasting glucose $\geq 7.0 \mathrm{mmol} / 1$ or treatment), hypercholesterolemia (total cholesterol $\geq 6.2 \mathrm{mmol} / 1$ ), hypertension (resting blood pressure $\geq 160 / 95 \mathrm{~mm} \mathrm{Hg}$ or treatment) and thyroid problems] or a diagnoses of cancer within the last 2 years.

${ }^{\mathrm{d}} \mathrm{A}$ diagnosis of major depressive disorder using the MINI according to DSM-IV criteria or severe depressive symptoms assessed with the Centre for Epidemiology Studies Depression Scale $(\geq 23)$. 
Table 2. Logistic regression models for the association between ER polymorphisms and anxiety disorders in elderly women.

\begin{tabular}{|c|c|c|c|c|c|c|}
\hline \multirow[t]{2}{*}{ Polymorphism } & \multirow[t]{2}{*}{ Genotype } & \multirow[t]{2}{*}{$\mathbf{N}$} & \multicolumn{2}{|l|}{ GAD } & \multicolumn{2}{|c|}{ Phobia } \\
\hline & & & OR $[95 \% \mathrm{CI}]$ & $\mathrm{p}$ & OR $[95 \% \mathrm{CI}]$ & $\mathrm{p}$ \\
\hline ESR1 rs2234693: & $\mathrm{TT}$ & 305 & 1 & & 1 & \\
\hline & $\mathrm{TC}$ or $\mathrm{CC}$ & 769 & $0.81[0.50-1.29]$ & 0.37 & $0.58[0.41-0.83]$ & 0.0029 \\
\hline ESR1 rs9340799: & AA & 443 & 1 & & 1 & \\
\hline & $\mathrm{AG}$ or $\mathrm{GG}$ & 630 & 0.99 [0.64-1.55] & 0.98 & $0.69[0.49-0.96]$ & 0.03 \\
\hline ESR2 rs1256049: & GG & 971 & 1 & & 1 & \\
\hline & GA or AA & 91 & 2.06 [1.09-3.87] & 0.02 & $0.62[0.30-1.25]$ & 0.18 \\
\hline ESR2 rs4986938: & GG & 368 & 1 & & 1 & \\
\hline & GA or AA & 707 & $1.18[0.73-1.90]$ & 0.51 & 1.06 [0.74-1.53] & 0.76 \\
\hline ESR2 rs1271572: & GG & 358 & 1 & & 1 & \\
\hline & GT or TT & 717 & $0.67[0.43-1.05]$ & 0.08 & $1.05[0.73-1.52]$ & 0.78 \\
\hline
\end{tabular}

